\title{
Impaired MMN in Patients: Attention-Dependent Augmentation of Nonparanoid vs. Paranoid Schizophrenic patients: \\ A Comparison with Obsessive-Compulsive Disorder and Healthy Subjects
}

\author{
Robert D. Oades, Alexandra Dittmann-Balcar, Dieter Zerbin, and Ina Grzella \\ University Clinic for Child and Adolescent Psychiatry, Virchowstr. 174, 45147 Essen, Germany
}

1997 Biological Psychiatry, 41, 1196-1210

\begin{abstract}
:
Mismatch negativity (MMN), in the deviant-minus-standard event-related potential (ERP) difference-waveform, may represent a working memory trace of the tone difference. Most but not all studies find $\mathrm{MMN}$ reduced in schizophrenic patients. This report investigates if differences may be attributable to experimental condition (diffuse vs. focused attention), component identification (N1like vs. N2-like), topographic distribution, and clinical condition (with/without paranoid-hallucinatory symptoms, $\mathrm{PH} / \mathrm{NP}$ ).

Comparisons were made for $12 \mathrm{PH}, 12 \mathrm{NP}$ schizophrenic patients with 13 obsessive compulsive and 25 normal control subjects. Frontal MMN reduction in schizophrenics largely resulted from an absence of an increase in focused attention conditions as in comparison groups. But there was a marked temporal activity locus in NP patients. These features were not reflected in other components except for a visible but non-significant NI-like temporal locus in NP patients. Further, schizophrenic patients did not show an increase in late positivity with focused attention like the comparison groups.

The results show that so-called automatic processing deficits (amount and locus of MMN) are best seen in situations requiring the activation of controlled attentional processes. It is suggested that impaired processing of irrelevant stimuli and reduced frontal MMN in NP patients may reflect reduced dopaminergic responsivity.
\end{abstract}

\section{Key Words:}

Event-related potentials, mismatch negativity (MMN), P3, attention, paranoid symptoms, schizophrenia, obsessive-compulsive disorder

\section{Introduction}

Mismatch negativity (MMN) can be seen after subtracting the event-related potential (ERP) obtained after a common (standard) stimulus from that elicited by a deviant stimulus. It is a negative-going waveform with peak latency between 100 and $250 \mathrm{~ms}$ depending on stimulus modality and the parameters of presentation. MMN has been studied mostly in the auditory modality and is regarded to represent a perceptual trace (Näätänen 1990) or working memory (Cowan et al 1993) for the difference between the two types of stimuli. It may usually arise as a result of involuntary automatic process-ing of information, but the

direction of focused attention can affect its size (Paavilainen et al 1993; Oades and Dittmann-Balcar 1995).

Schizophrenia has long been recognized as an illness that includes impairments of controlled (voluntary) attentional processing (Callaway and Naghdi 1981; Straube and Oades 1992). More recently consensus has emerged that the automatic processing of information can also be impaired (Hemsley 1994). Non-paranoid psychotic patients may experience difficulty in carrying out automatic processing (e.g., covert orienting of attention, Carter et al 1994), while paranoid 
schizophrenics may have problems in monitoring automatic processing and hence controlling it (Frith 1992; Strauss 1993). The question therefore arises whether schizophrenics show illness-specific MMN impairments and if so, are these impairments associated with a particular type of psychotic process or group of symptoms?

MMN as a function of tone-pitch and presentation rate was first reported to be attenuated in male schizophrenics (mixed subtype and illness duration) with respect to age and gender-matched healthy subjects by an Australian group (Shelley et al 1991). This group replicated this finding with auditory stimuli varying in duration and with unmedicated patients (Catts et al 1992, 1995). They showed that even though the controls' $M M N$ varied with stimulus duration, MMN amplitude was approximately halved in patients (respectively $-4.5 \mu \mathrm{v}$ and $-2.5 \mu \mathrm{v}$ ). Oades et al (1992b, 1993) reported a severe MMN reduction in young acutely ill psychotic patients diagnosed with paranoid or other nonparanoid forms of schizophrenia where the stimuli varied in pitch and presentation frequency. Javitt et al (1993) also con-firmed an attenuation of MMN in a mixed group of chronic schizophrenics of a similar age to those studied by the Australian group with stimuli varying in pitch.

Intriguingly, Oades (1995) represented his analysis in terms of patients with and without active paranoid-hallucinatory symptoms $(\mathrm{PH}$ from SANS and SAPS ratings, Andreasen 1983, 1984). While frontal MMN in normal healthy subjects averaged about $4.5 \mu \mathrm{V}, \mathrm{PH}$ patients showed a significant reduction to about $2.2 \mu \mathrm{V}$ and non-paranoid patients (NP) showed virtually no frontal MMN. In contrast, the raw data showed NP patients with posterior temporal peaks.

These data imply that there was both a trait (schizophrenia) and a state (active symptoms) contribution to $\mathrm{MMN}$ reduction. The aspect of trait-dependency has since been emphasized by Javitt et al (1995a) who reported similarly attenuated $\mathrm{MMN}$ from remitted and hospital-ized subchronic patients; however this group has recently suggested that lower MMN amplitude correlates with less severe negative symptoms (Umbricht et al 1995). This implies a statedependency albeit apparently opposite to that of Oades (1995). Further, problems of generalization and interpretation also arise since two groups have reported not being able to detect reduced $\mathrm{MMN}$ in schizophrenia (O'Donnell et al 1994; Kathmann et al 1995).

Catts et al (1992) obtained their results while subjects were distracted from actively attending to the tones by the simultaneous performance of a visual reaction time task, rather like Kathmann et al (1995) O'Donnell et al (1994) found no significant attenuation in chronic schizophrenics who were distracted by reading at the time of being presented with tones varying in pitch, rather like Javitt et al (1993). Thus the reported differences are not easily explained by methods (stimulus feature varied, accessory activity) or the age of the patients.

It seemed however, that this apparent paradox might be resolved by comparing MMN derived in a passive presentation (diffuse attention) with that derived from the same two types of tone irrelevant to the active discrimination of a third tone (compare accessory task above). Further we analyse such data in a) an extended patient group, and with b) raw and vector normalized data in order to emphasize symptom-group specificity of the purported amplitude impairment between psychiatric groups and the topographic differences within the schizophrenic group.

Between-group specificity was achieved by studying a group of patients with obsessivecompulsive disorder (OCD). As argued elsewhere (Oades et al 1994) this group is of interest for etiological reasons (the reported incidence of an obsessive phase in the ontogeny of psychosis), putative anatomical and biochemical functional impairment (orbito- vs. dorsolateral frontal cortex, serotonin vs. dopamine), and anomalous attentional function. The within-group specificity was examined by normalizing topographically recorded data with a vector taking account of the potentials recorded at 
all sites. The intention here was to see if the distinction previously drawn from raw data could be an arte-fact (see Methods below).

As a subsidiary goal other positive and negative deflections found in the difference waveform are described to explore their potential for either mirroring the schizophrenic impairment or, under different conditions, possibly expanding differentially to obscure the MMN impairment. (For example, one could posit that an enlarged positive component with P2-like latency could

Table 1.

Characteristics of Subject Groups (Means and Range for Data) and Discrimination Performance in the Active ERP Session

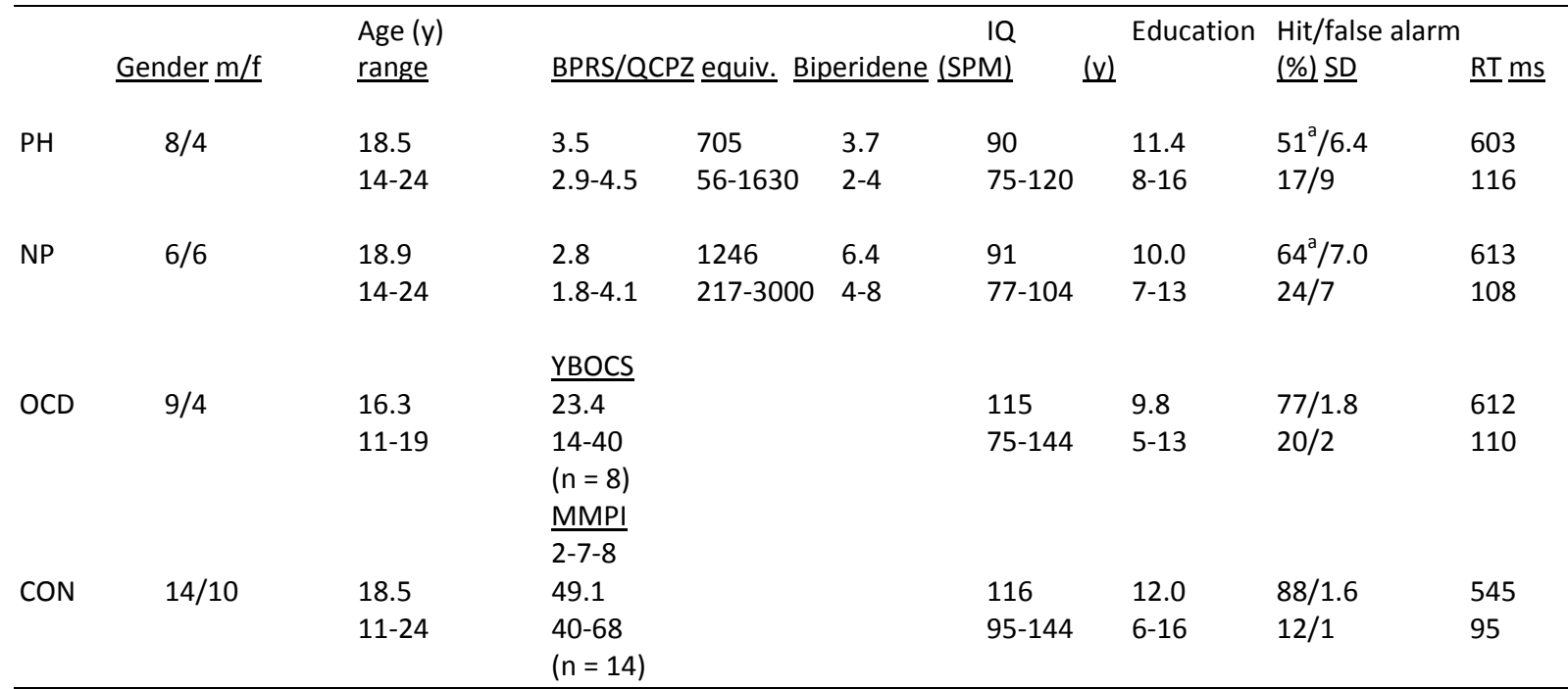

$\mathrm{PH}=$ paranoid (1 neuroleptic- and 5 biperidene-free); NP = nonparanoid ( 2 neuroleptic- and 7 biperidene-free); $\mathrm{CPZ}=$ chlorpromazine equivalents (NP received non-significantly more medication; Rey et al 1989); $O C D=$ obsessive-compulsive disorder (all medication-free); $\mathrm{CON}=$ healthy controls, BPRS (brief psychiatric scale of 7, score per question (18)); YBOCS (Yale-Brown scale for assessment of obsessive compulsive symptoms); MMP1 (Minnesota multiphasic personality inventory, schizotypal scales 2-7-8 (40-60 = normal, subjects $>16 \mathrm{yr})$ ); IQ from Raven's standard progressive matrices, education (years of schooling and study); RT (reaction time to auditory target stimulus). a Both schizophrenic groups were less accurate than OCD and CON groups (both measures; $F(6,130)=7, p<0.0001$ ) but there were no reaction time differences.

overlap and obscure preceding or succeeding negative components). It should here be noted that there are reports in differencewaves of N1-like (early Nd, Woods et al 1993), P2-1ike and P3-1ike components (Yamaguchi et al 1995) and of their scalp topography (Oades et al 1995). Indeed O'Donnell et al (1994) did report on a "P2b" component in passive and active MMN measures, reminiscent of the paradigm described here, that was specifically attenuated in the active measure in schizophrenic patients. Further Javitt et al (1995b) confirmed their findings of a reduced $M M N$ in schizophrenics, but analyzed data for the earlier of two negative going components in the difference waveform which showed positive deflections before, between, and after the potential MMN components. Hence the analysis in the current report was briefly expanded to these other deflections.

In summary we expected to confirm MMN amplitude reduction in schizophren-ics and predicted that it would not increase as in controls in the focused attention condition; in addition it was expected that the topographic analysis would confirm decreased frontal MMN (N2-1ike) activity seen in the raw data of nonparanoid schizophrenics and that this would be reflected in the earlier N1-like component (coinciding with the reported start of $\mathrm{MMN}$ ) as well as in the subsequent P3-like late positivity.

\section{Methods}

Subjects

From 31 newly admitted patients diagnosed with a schizophreniform psychosis 
(DSM-IIIR and ICD-9) 24 provided ERP data. Diagnosis by a clinical psychiatrist was confirmed by a clinician and three psychologists (after rating a semi-structured clinical inter-view; Spearman rho 0.64- 0.75 for 64 questions, Andreasen 1983, 1984). (Patients were excluded on diagnostic grounds (2) or if they did not discriminate between the tones (2) and provide artefact free data (3). Schizophrenic patients $(\mathrm{SCH})$ were divided into paranoid hallucinatory $(\mathrm{PH})$ and non-paranoid (NP) groups according to a median split on the SAPS scale (Andreasen 1984).

At the same time 13 medication-naïve $O C D$ patients were rated on the Yale-Brown Obsessive-Compulsive scale and tested. From a pool of 40, 25 young healthy case-controls were matched pair-wise to the psychotic patients for gender and age within 6 months. (One extra was added for a young OCD patient). They reported themselves free of past or present psychiatric illness, organic disorder, or substance abuse (urine samples were taken) and medication, except contraceptive substances. This design along with our reports on ERP development from 822 y (Oades et al 1996b) precludes explanations of differences in terms of age (Table 1, demography). Testing followed approval of the protocol by the clinic management, agreement of the therapists and nursing staff to the tests in principle and the time-point in each case, and the cooperation, understanding, and consent of the patient and the legally responsible adult.

\section{Recording Procedure}

A three-tone oddball was presented in successive passive and active discrimination sessions (diffuse vs. focused attention: details in Oades et al 1995). Tones, from an exact gate-function-generator were played over DT48 (Beyer Dynamics) earphones. A hundred tones per trial-block were presented in a Bernoulli sequence with the proviso that a deviant tone should not follow a deviant tone $(0.8,1.4$, and $2.0 \mathrm{KHz}$ tones, $\mathrm{p}=70 \%, 15 \%$, and $15 \%$ respectively, at $65 \mathrm{dBspl}$ with $50 \mathrm{~ms}$ duration, rise $/$ fall time $=10 \mathrm{~ms}, \mathrm{SOA}=1 \cdot 2-1.7$ $\mathrm{sec})$. Prior to recording, normal hearing thresholds up to $7 \mathrm{KHz}$ were ascertained for all subjects with an Audio-Med audiometer
BCA3: where any left/right hearing thresholds varied by $5 \mathrm{~dB}$ or more, levels were adjusted accordingly.

Subjects, comfortably seated in a Faradayroom were asked to fixate on a small cross on the wall to help reduce eye movement during recordings. They were told that first there would be a baseline recording with nothing to do (passive session). Afterwards they were asked to discriminate between the tones by raising a finger from a metal contact as fast but as correctly as possible after the $1.4 \mathrm{KHz}$ tone. This was practiced before recording in the active session. The accuracy of schizophrenic patients was worse than the OCD or control subjects, but reaction times did not differ significantly (Table 1 ).

Recordings were made from 19 sites (10:20, Electrocap) using linked ear reference with a balanced impedance of $<2 \mathrm{KOhm}$ at all sites. Fpz and $\mathrm{Oz}$ were used as separate ground electrodes as required for data collection on the Siemens EEG 21 and Compaq 386 pc (sampled at $250 \mathrm{~Hz}$ for $1024 \mathrm{~ms}$ include-ing $50 \mathrm{~ms}$ pre-trigger time). Amplification by $12 \mathrm{~K}$ used a band pass 0.3 to $70 \mathrm{~Hz}$ (6dB/octave). Electro-oculographic (EOG) artefact $(>65 \mu \mathrm{V})$ recorded above the eye was eliminated. Data were evaluated offline with gross electromyographic (EMG) interference reduced by the low pass filters and, when necessary, a digital low-pass, rectangular filter. The sampling rate and the normalization of latency data reduced problems of aliasing and hardware induced delays in the topographic analysis of latencies (Pivik et al 1993). The mean proportion of trials (SD) removed for artefact was CON $22 \%$ (10), OCD 35\% (19), PH 38\% (21), NP 29\% (14). Only artefact- and error-free trials were evaluated; accepted common /rare tones per group averaged CON 205/67, OCD 199/67, PH 256/57, NP 210/57.

\section{ERP Measures and Statistical Methods}

ERPs were evaluated at F7, F3, Fz, F4, F8; C3, Cz, C4; P3, Pz, P4; T3, T4, T5, and T6. From these data and data from two $\mathrm{Fp}$ and two $\mathrm{O}$ sites on a $5 \times 5$ grid along the axes of the 10:20 system, topographic maps were made using a horizontal and vertical linear 
Interpolation algorhythm to establish a matrix of $180 \times 180$ points.

Difference-waves were derived from ERPs after the deviant $(2 \mathrm{KHz})$ minus the standard tones $(0.8 \mathrm{KHz})$. Peaks were identified relative to the first large negative peak (N1-like, occurring 80-140 ms post-stimulus) and the start of the earliest but largest positive P3-like deflection (window 240-540 ms). A P1-like component (30-100 ms) was the largest positive-going dip before the first large negative peak, with a P2-like positive deflection (120-240 ms) following this negativity and preceding the window for the P3-like component. MMN (N2-like) was the largest negative peak: it occurred between the P2- and P3-like peaks (140-300 ms).

\section{Data Analysis}

A three-way multivariate analysis of variance (MANOVA) was performed with the four groups (PH, NP, OCD, and CON) as between subjects factor and the two conditions (passive and active, repeated measures) along with the recording sites (not Fp and $\mathrm{O}$ sites) as within subjects factors (repeated measures). Raw $(F z, C z, P z)$ and vector normalized data (15 sites) were analyzed for quantitative and topographic analysis, respectively. The vector was the mean of each component measure at each site, divided by the square root of the sum of the squared mean measures for the 15 recording sites (Naumann et al 1992). Significant results are reported after Hotelling's $\mathrm{T}^{2}$ test as an assessment of potential between measure differences (Faux and McCarley 1990) and SPSSX "averaged" tests for 15 sites after correction with the appropriate Greenhouse-Geisser e-factor. A significant $\mathrm{T}^{2}$ result preceded further analysis (in terms of SPSS aver-aged tests and progress from two- to three-way analyses). As the focus of the report is on the size and topography of group specific changes with attention condition the analysis concentrates on the three-way interaction (Table 2); however, changes of size and topography with condition, independent of group (two-way interaction, SPSSX-aver-aged tests) are also reported in the text.

To determine the locus of the effect of each condition a significant group-bycondition-by-site interaction was followed by a one-way analysis of variance (ANOVA) and a post-hoc Scheffe test at $\mathrm{Fz} / \mathrm{Cz}$ between groups. (The ANOVA is cited and use of the term Scheffe denotes an alpha significance level of $5 \%$ was exceeded). To find where the topographic effect lay paired Student $t$ tests were performed within each group between the conditions at the three midline and six most lateral sites. The Bonferroni procedure then cautions adjustment of alpha to $0.14 \%$.

\section{Results}

Figure 1 shows a major negative component in the passive difference waveform (MMNp) with an N2-like latency (mean 204 ms SD 39 (CON) to 253 ms SD 47 $(\mathrm{PH})$ at $\mathrm{Fz}$ ) followed by a major late positive deflection with a P3- like latency (mean 331 ms SD 71 (OCD) to 369 ms SD 72 (PH) at Pz). These two components are the focus of this study. This analysis extends our reports of decreased fronto-central MMN and reduced late positivity in the two schizophrenic groups (Oades et al 1993, 1996a). Here we concentrate on the changes recorded between passive and active conditions (MMNp and $\mathrm{MMNa}$ ) and then their topography. 
Table 2.

Summary of MANOVA for Subject-Group x Condition (Diffuse/Focused Attention) $x$ Site Interactions for 5 ERP Peak Amplitudes (and MMN and P3-1ike Peak Latencies) in the Deviant-Minus-Standard Waveform

\begin{tabular}{|c|c|c|c|c|c|c|c|c|c|}
\hline \multirow[b]{2}{*}{ Peak } & \multicolumn{4}{|c|}{ Hotellings I $2 \underline{\text { Test }}$} & \multicolumn{5}{|c|}{ Site-Averaged Tests } \\
\hline & Data & $\mathrm{df}$ & $\mathrm{F}$ & $\mathrm{p}$ & $\mathrm{df}$ & $\mathrm{F}$ & $\mathrm{p}$ & Epsilon & Sig \\
\hline \multirow[t]{2}{*}{ P 1} & Raw & 42,131 & 2.3 & 0.000 & 42,812 & 1.6 & 0.013 & 0.405 & $a$ \\
\hline & Norm & 42,131 & 2.2 & 0.000 & 42,812 & 1.9 & 0.000 & 0.409 & c \\
\hline \multirow[t]{2}{*}{ N1 } & Raw & & 1.4 & 0.069 & & 1.4 & 0.042 & 0.501 & $a$ \\
\hline & Norm & & 1.2 & 0.203 & & 1.1 & 0.355 & 0.466 & NS \\
\hline \multirow[t]{2}{*}{ P2 } & Raw & & 1.2 & 0.257 & & 1.8 & 0.001 & 0.448 & b.a \\
\hline & Norm & & 0.9 & 0.586 & & 1.5 & 0.019 & 0.451 & $a, d$ \\
\hline \multirow[t]{2}{*}{ MMN } & Raw & & 1.9 & 0.003 & & 2.3 & 0.000 & 0.483 & $\mathrm{c}$ \\
\hline & Norm & & 2.1 & 0.001 & & 1.7 & 0.007 & 0.450 & $\mathrm{~b}$ \\
\hline Raw & Latency & & 1.1 & 0.285 & & 1.1 & 0.270 & 0.532 & NS \\
\hline Norm & & & 1.0 & 0.465 & & 1.1 & 0.332 & 0.542 & NS \\
\hline \multirow[t]{2}{*}{ P3 } & Raw & & 1.8 & 0.006 & & 2.9 & 0.000 & 0.459 & $\mathrm{c}$ \\
\hline & Norm & & 1.1 & 0.370 & & 1.2 & 0.222 & 0.430 & NS \\
\hline Raw & Latency & & 1.3 & 0.133 & & 1.6 & 0.008 & 0.534 & $a$ \\
\hline Norm & & & 1.4 & 0.095 & & 1.5 & 0.022 & 0.552 & $a$ \\
\hline
\end{tabular}



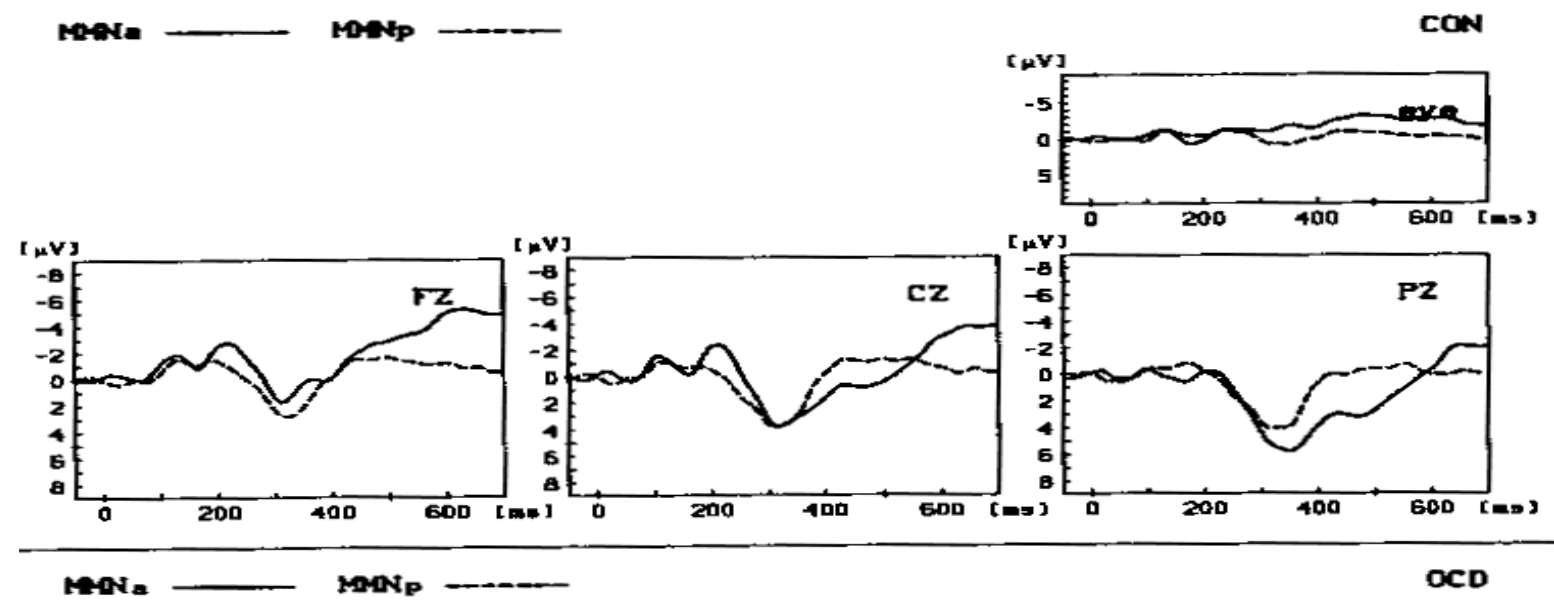

Mas.

$\operatorname{mon}$
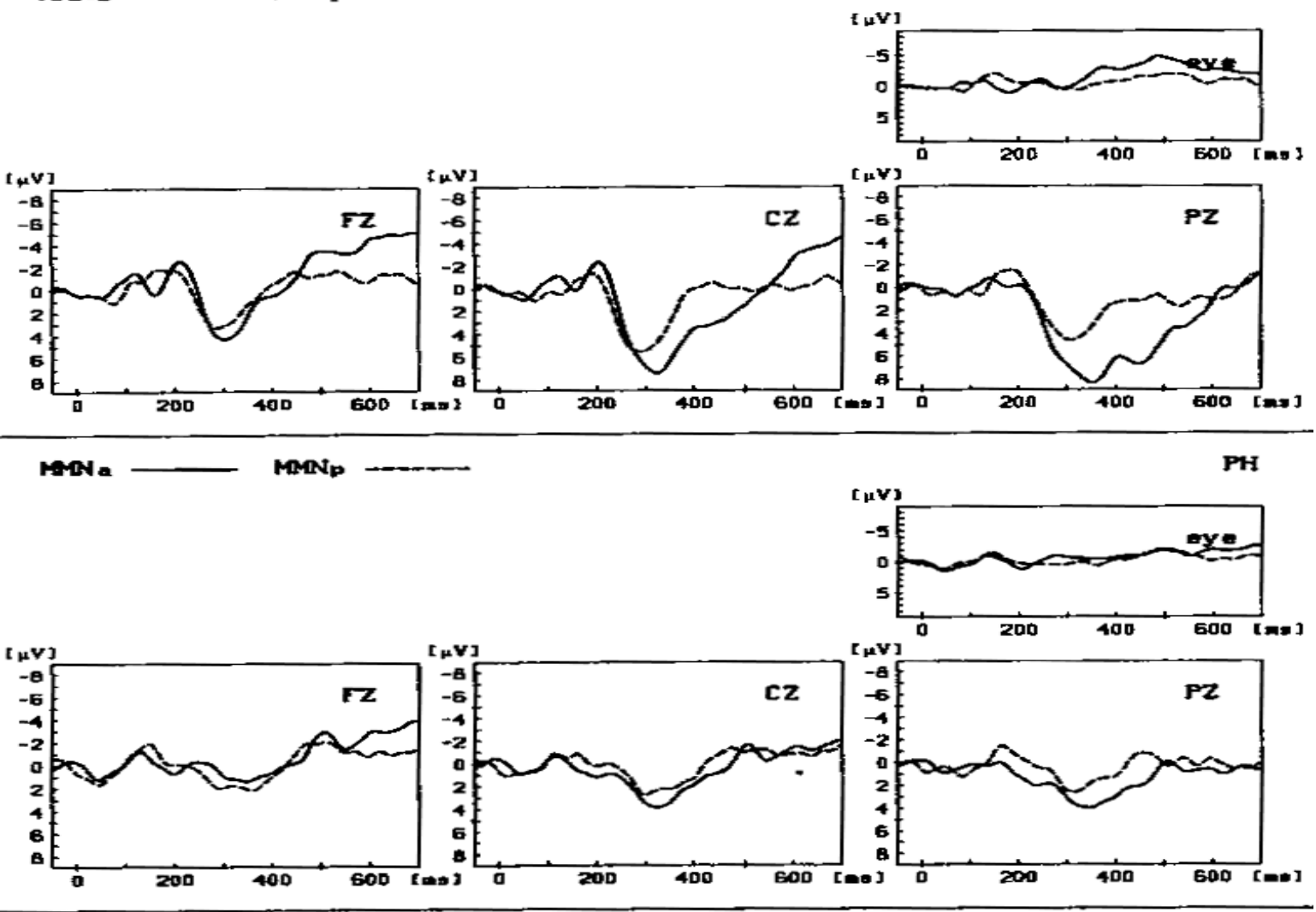

MNA

Manp
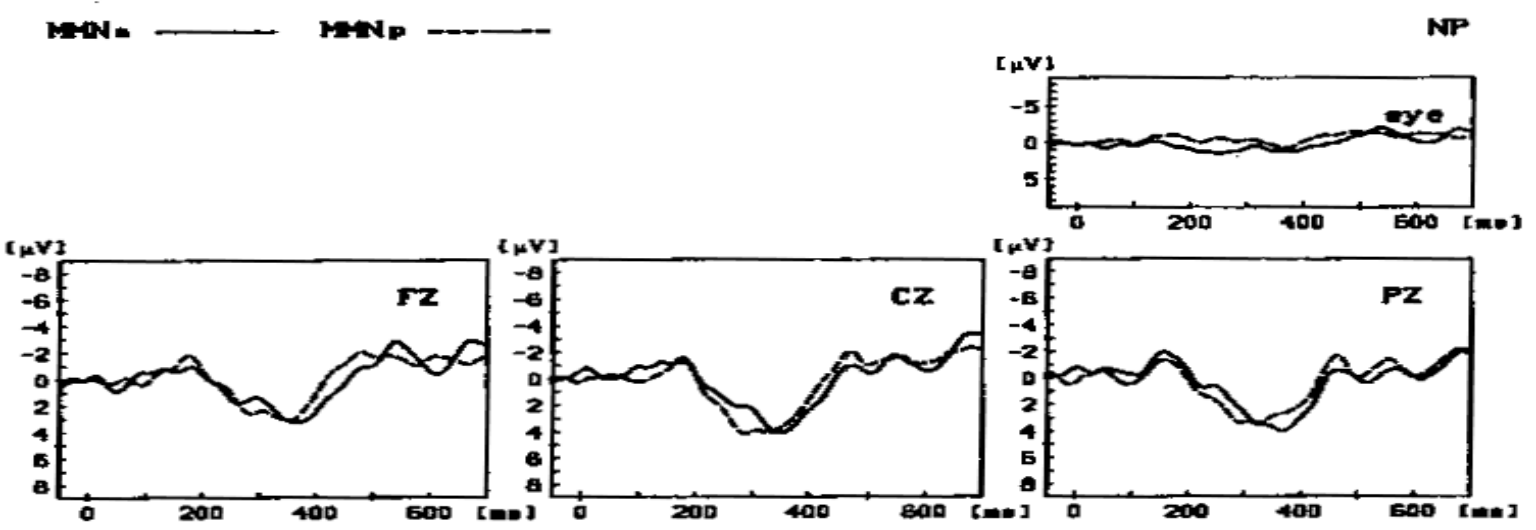

Figure 1. Grand mean 'deviant-minus-standard' difference-waveforms $(\mu \mathrm{V})$ for four subject groups in four descending panels, respectively, for healthy controls (CON, upper), patients with obsessive-compulsive disorder $(\mathrm{OCD})$, paranoid-hallucinatory psychosis $(\mathrm{PH})$ and non-paranoid psychosis (NP, lower). Records from anterior to posterior sites $(\mathrm{Fz} \mathrm{Cz}, \mathrm{Pz})$ extend for $700 \mathrm{~ms}$ after tone-presentation in the passive (MMNp) and active discrimination condition ( $\mathrm{MMNa}$ ): insets show EOG representations of eye movements. 


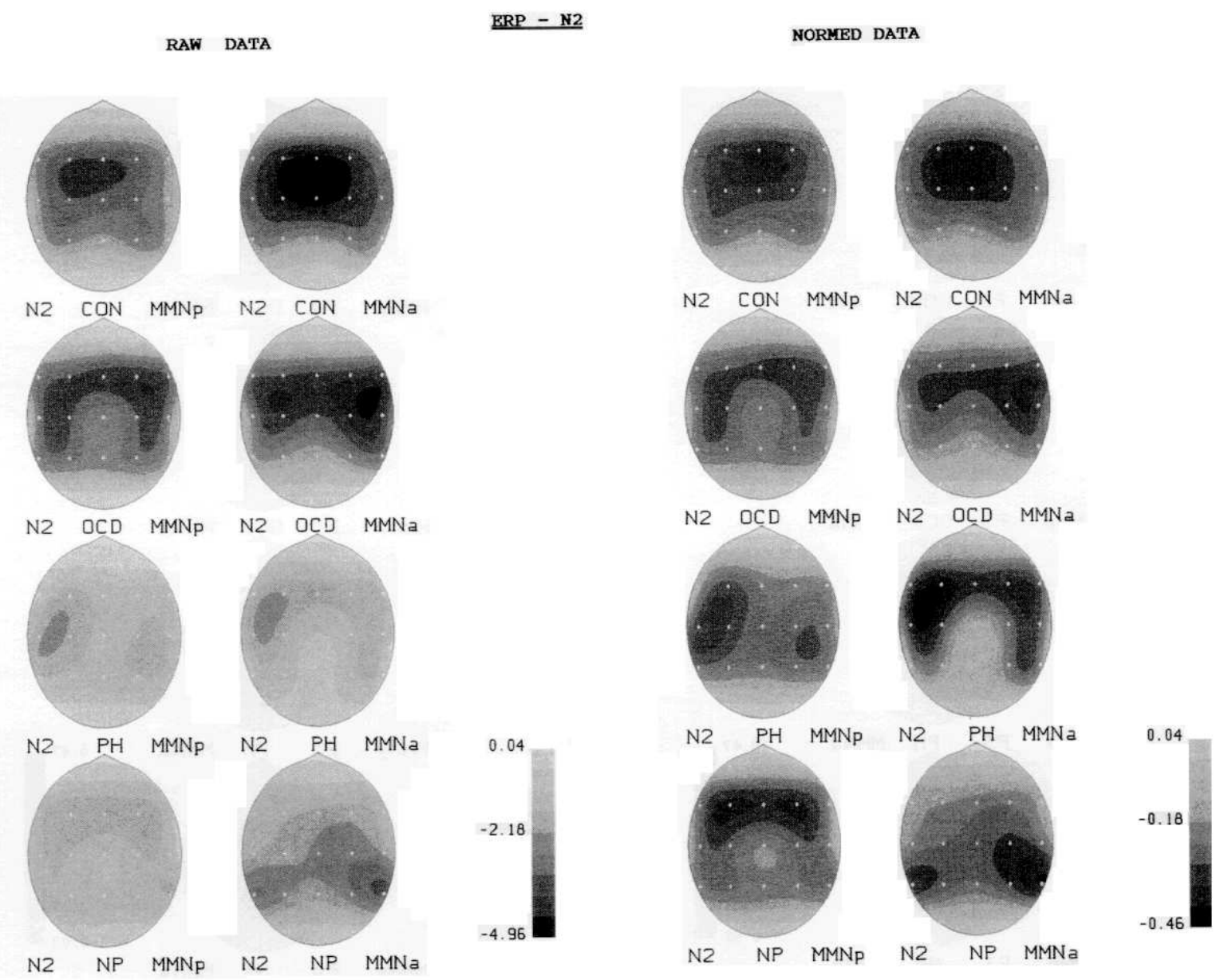

Figure 2. Topographic scalp distribution (nose points up the page) of the amplitude of the N2-1ike component of the difference-wave (mismatch negativity). Raw data are shown on the left side for four subject groups (see Figure 1 legend) in the passive (MMNp) and active conditions (MMNa: scale bar 0-5 $\mu \mathrm{V}$ ). Note the reduced values, especially at frontal sites in schizophrenic patients (PH, NP). Vector-normalized data are shown on the right side (scale bar adjusted to the range of raw data values). Note the lateralization in patients and temporal peaks in NP patients in the active condition (MMNa).

\section{N2- \& P3-1ike Difference-Wave Components}

For the N2-1ike MMN component, condition $\mathrm{x}$ site interactions for raw and normalized data showed a general trend for an increase of negativity with increased focused attention across groups $(F(14,812)=2.8 / 2.6, \quad e=.483 / .450$, corrected $\mathrm{p}<.01 / .05)$ which was confirmed for $\mathrm{Cz}$ posthoc $(t=-2.11, p=.039)$. Significant group $x$ site ANOVAs on raw and normalized data further allow an inspection of the role of group in group $\mathrm{X}$ condition $\mathrm{X}$ site interactions $\left(F(14,131)=2.04 / 2.12, p<.003\right.$, Hotelling's $\left.T^{2}\right)$.

Significant 3-way interactions for raw data (Table 2) were attributable to increases in the focused attention condition in the controls at $\mathrm{Fz}$ and $\mathrm{Cz}$ ( $\mathrm{t}=-2.68-2.98, \mathrm{p}=.013-.007)$. In the patient groups non-significant increases and decreases were registered at midline sites. Thus in the active (but not the passive) condition a much larger MMN amplitude was recorded in the controls at Fz vs. the NP group (4.62 vs. $1.76 \mu \mathrm{V}$ ) and at $\mathrm{Cz}$ vs. the $\mathrm{PH}$ group (4.84 vs. $0.55 \mu \mathrm{V} ; \mathrm{F}(3,61)=4.22 / 5.82, \mathrm{p}=.009$ .002 Scheffe).

The significant 3-way interaction with normalized data (Table 2) reflected a) the decrease over frontal areas in the NP group from passive to active conditions (where other patients increased and controls showed no change, Figure 2) and b) the increase at temporal sites in the NP and OCD groups from passive to active conditions ( $t=-2.92, p=.013$ ) where controls showed no change and $\mathrm{PH}$ 
patients a decrease $(t=+2.17, p=.05)$. Thus frontal MMN in NP patients was between half and a quarter of that in other subjects (e.g., $F 8, F(3,61)=4.59, p=.006$, Scheffe) while temporal MMN amplitude in NP patients was three times that in $\mathrm{PH}$ or CON subjects (e.g., T6, $F(3,61)=8.14, p=.0001$,Scheffe; Fig 2). There were no significant effects for latency measures.

An increase of late P3-like positivity in the difference waveform with increased focused attention was shown by the condition $x$ site interaction for raw and normalized data $(F(14,812)=41 / 31, \quad e=.459 / .430$, corrected $\mathrm{p}<.001)$. The group $\times$ site ANOVAs for normalized and raw data both attained a trend level of significance, implying that in group $x$ condition $X$ site interactions the within group effect of condition would predominate $(F(42,131)=1.44 / 1.46, p<.06$, Hotelling's T2).

The three-way interaction for the raw data (Table 2) showed that the increase was significant at $\mathrm{Pz}$ only in the OCD and CON groups ( $\mathrm{t}=+3.13-4.28, \mathrm{p}=.009-.0001)$; however, in healthy subjects the increase was also detectable at $\mathrm{Cz}(\mathrm{t}=+2.65, \mathrm{p}=.014)$ and $\mathrm{Fz}$ $(\mathrm{t}=+1.90, \mathrm{p}=.07)$. The low amplitude in psychotic groups vs high amplitude in comparison groups was confirmed for the OCD vs. PH groups $(F(3,61)=3.77, p=.015$, Scheffe, Figure 3).

For the normalized topographic data a significant 3-way interaction did not follow the marked condition by site interaction $(F(14,812)=31.3, \quad e=.430$, corrected $p<.01)$.
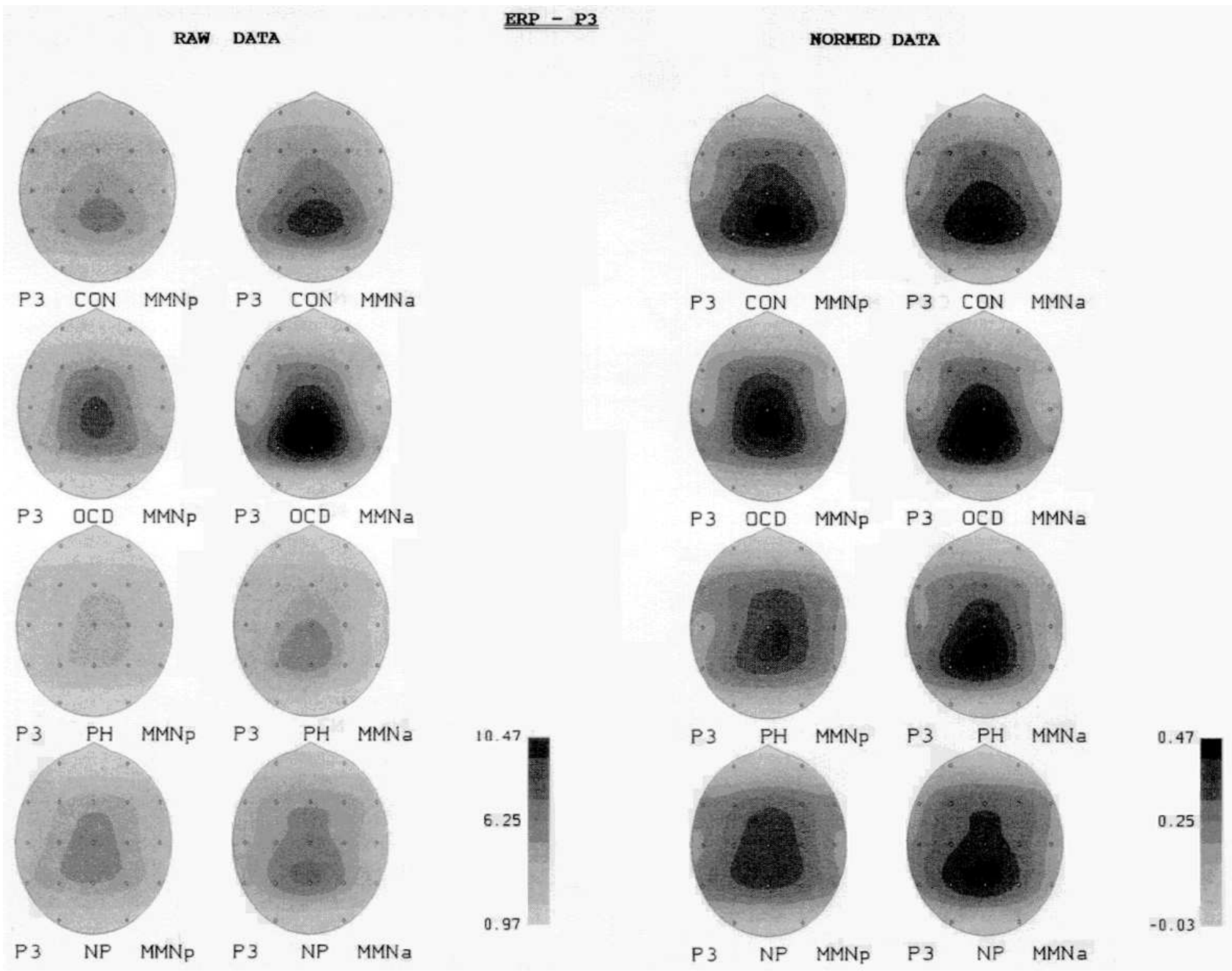

Figure 3. Topographic distribution of the amplitude of the P3-1ike component of the difference-wave. Raw data are shown (left) for 4 subject groups (see Figure 1 legend) in passive (MMNp) and active conditions MMNa). Note the increased values in the active condition (MMNa all groups) and the low values in schizophrenic patients (PH, NP). Vector-normalized data are shown on the right. Note the similar centro-parietal distribution of activity between groups. 
Post-hoc $t$ test comparisons indicated a decreased contribution from lateral frontal and temporal sites with focused attention across groups (F7, F8, T3, T4; $t=-1.64--6.19, p$ $=$. .l-.0001). The lack of group topographic differences in the normalized data is illustrated in Figure 3.

Across groups there was a significant increase of latency with the onset of focused attention (condition $\times$ site, raw data, $\mathrm{F}(14,812)=5.6, \mathrm{e}=.534$, corrected $\mathrm{p}<.01)$; however, the group $\mathrm{x}$ site interaction was marginal $\left(F(42,131)=1.6, p=.03\right.$, Hotelling's $\left.T^{2}\right)$ and the larger increase in patient groups only attained trend significance in the three-way interaction (Table 2, compare Figure 1).

\section{Precursor-like Components in the Difference-Wave form}

Figure 1 shows a negative component in passive and active difference wave-forms (MMNp and $\mathrm{MMNa}$ ) smaller than the succeeding N2-1ike MMN component and with an earlier N1-like latency (mean $126 \mathrm{~ms}$ SD 40 (OCD) to $130 \mathrm{~ms}$ SD 30 (PH) at Fz in the passive condition). It was preceded by a Pl-like deflection (mean latency 61 ms SD 24 (CON) to $73 \mathrm{~ms}$ SD 27 (OCD) at $\mathrm{Cz}$ ) and succeeded by a small positive deflection with a P2-1ike latency (mean 150 ms SD 43 (CON) to $196 \mathrm{~ms}$ SD $56(\mathrm{PH})$ at $\mathrm{Cz}$ ). There were no significant group or condition effects for these latency measures.

For the Pl-like component significant condition $x$ site interactions for both raw and normalized data $(F(14,812)=6.6 / 6.0$, $e=.212 /$ .405 , corrected $p<.01)$ showed that, independent of subject group, there was generally a trend for an increase at lateral frontal and for a decrease at postero-lateral temporal sites in the active condition $(t= \pm$ 2.41, $\mathrm{p}=.019$ ).

The 3-way interactions for normalized data (Table 2) confirmed the bilateral temporal decrease in both schizophrenic groups ( $t=-3.4$, $\mathrm{p}<.006)$, and particularly in the NP with respect to comparison groups $(F(3,61)=$ 7.3/8.1, $\mathrm{p}=.0003-.0001$, Scheffe for PH and NP at T5, NP at T6). This should be viewed in the context that P1 peaks had fronto-central maxima in the psychotic and centro-parietal loci in the comparison groups (Figure 4). Further, the absence of a conventionally significant overall group by site effect (Hotelling's $\mathrm{T}^{2} \mathrm{c} .1 \%$ ) serves to emphasize the role of condition in producing a differential 3way interaction.

For the N1-like component significant condition $\mathrm{X}$ site interactions for both raw and normalized data $(F(14,812)=3.6 / \quad 3.2$, $\mathrm{e}=.466 / .501$, corrected $\mathrm{p}<.01$ ) implied a possible increase in (fronto-central) negativity across groups in the active condition, but this could not be confirmed post-hoc. There were no significant group interactions (e.g., Table 2). Topographic maps (Figure 5) show all groups with a more or less frontal distribution and the NP group with an additional minor left temporal peak.

The condition $\mathrm{X}$ site interaction for the $\mathrm{P} 2$ 1ike component was significant for raw data $(F(14,812)=2.3, p<.05)$, but Hotelling's and averaged tests conflicted on the normalized data. The group by site interaction was not significant. There were isolated but not systematic significant decreases of positivity over temporal sites in some patient groups.

Three-way interactions including group (Table 2) showed a trend for patients, particularly the $\mathrm{PH}$ group, to show more positivity at $\mathrm{Fz}$ in the passive (raw data) and active condition (normed data; both $F(3,61)=5.0 / 6.5, p=.004-.0007$, Scheffe). The topographic maps (not shown) illustrated more of a frontal spread of positivity in patient groups from the usual posterior maximum. The result is merely a trend, but is strongly consistent with the MMN results described above.

\section{Discussion \\ Main Effects}

An attenuated MMN amplitude was confirmed for schizophrenic patients. This was exaggerated as a function of the increased MMN in comparison with (not schizophrenic) subjects associated with the focusing of attention required in the discrimination condition. While the topography of MMN in patients showed signs of lateralization in the 

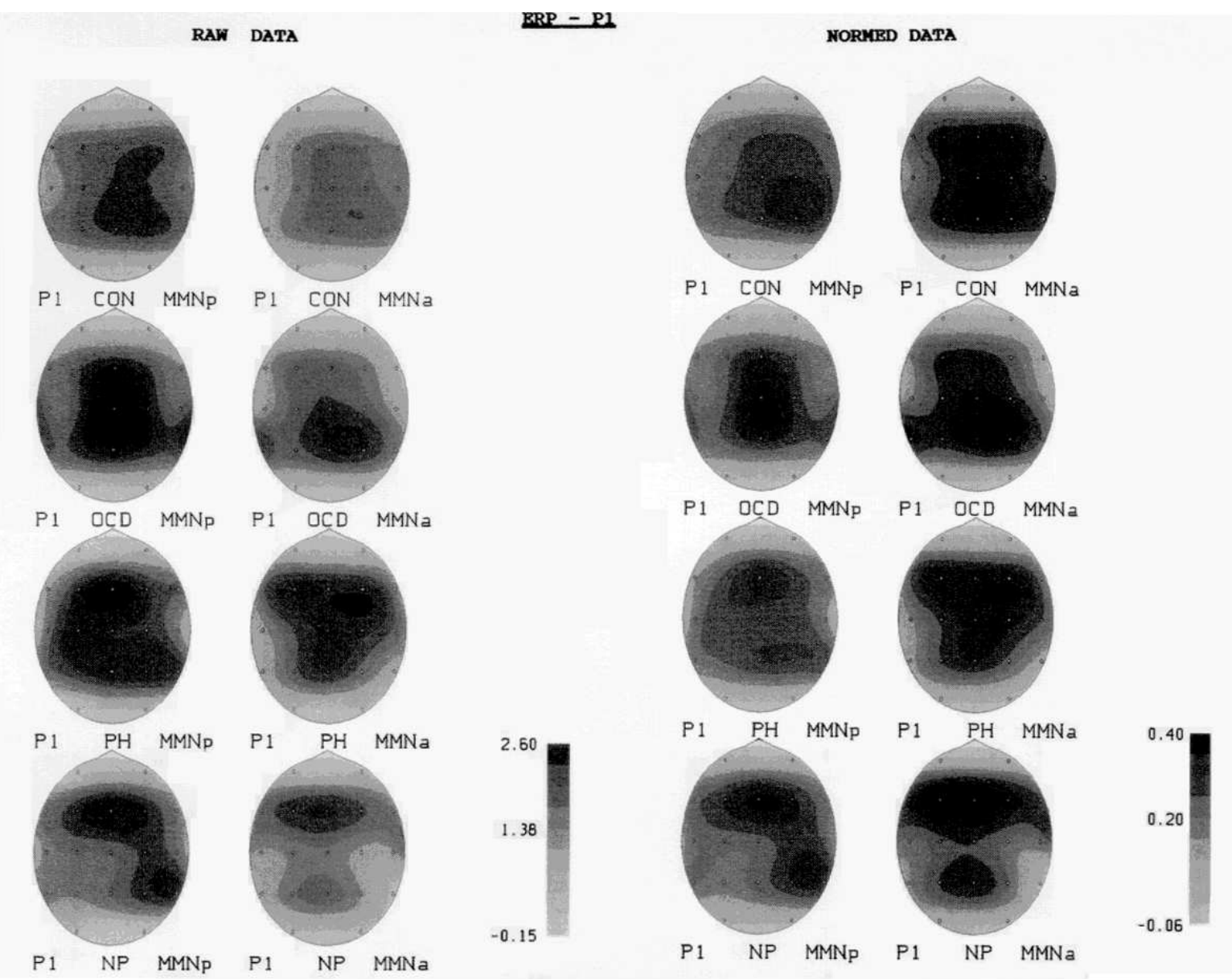

Figure 4. Topographic distribution of the amplitude of the Pl-like component of the difference-wave. Raw data (left) are shown for 4 subject groups (see Figure 1 legend) in passive (MMNp) and active conditions (MMNa). Vector-normalized data are shown on the right. Note the fronto-central vs. centro-parietal loci in schizophrenic vs comparison groups and the bilateral temporal decrease in the active condition (especially NP).

passive condition, a postero-lateral locus in non-paranoids was unexpectedly restricted to the active condition. Although the earlier N1like deflection tended to increase in the attention condition in all groups against expectations, there were no statistically confirmed group differences as with the later N2-like MMN component.

The subsequent P3-1ike positive deflection in schizophrenic patients did not increase significantly between diffuse and focused attention conditions as in control and OCD groups. But while smaller in both schizophrenic groups in passive and active conditions, it did not show topographic differences between groups. The early PI-like deflection did not reflect changes seen in later positive deflections but did partially mirror later $\mathrm{MMN}$ changes (e.g., frontal increase and temporal decrease of positivity in schizophrenic patients). The focused attention condition induced few effects on Pl-like topography except for a general decrease of involvement of lateral sites; however, the P21ike deflection extended more frontally in all 3 patient groups than in controls (again mirroring $\mathrm{MMN}$ ), but this was independent of the condition (unlike MMN).

\section{Effect of Condition}

In Figure 3 it may be seen that while schizophrenic groups showed reduced MMN in both diffuse and focused attention conditions, the effect was larger in the active condition as the increase shown by control and OCD groups did not occur. This has practical and theoretical importance. The practical importance is that reports of no MMN reduction in schizophrenics may reflect a) the selection of subjects with relative-ly intact automatic information process-ing and/or b) that the subjects were not actively attending to something else,--a condition that from the present results appears to enhance the MMN difference. 

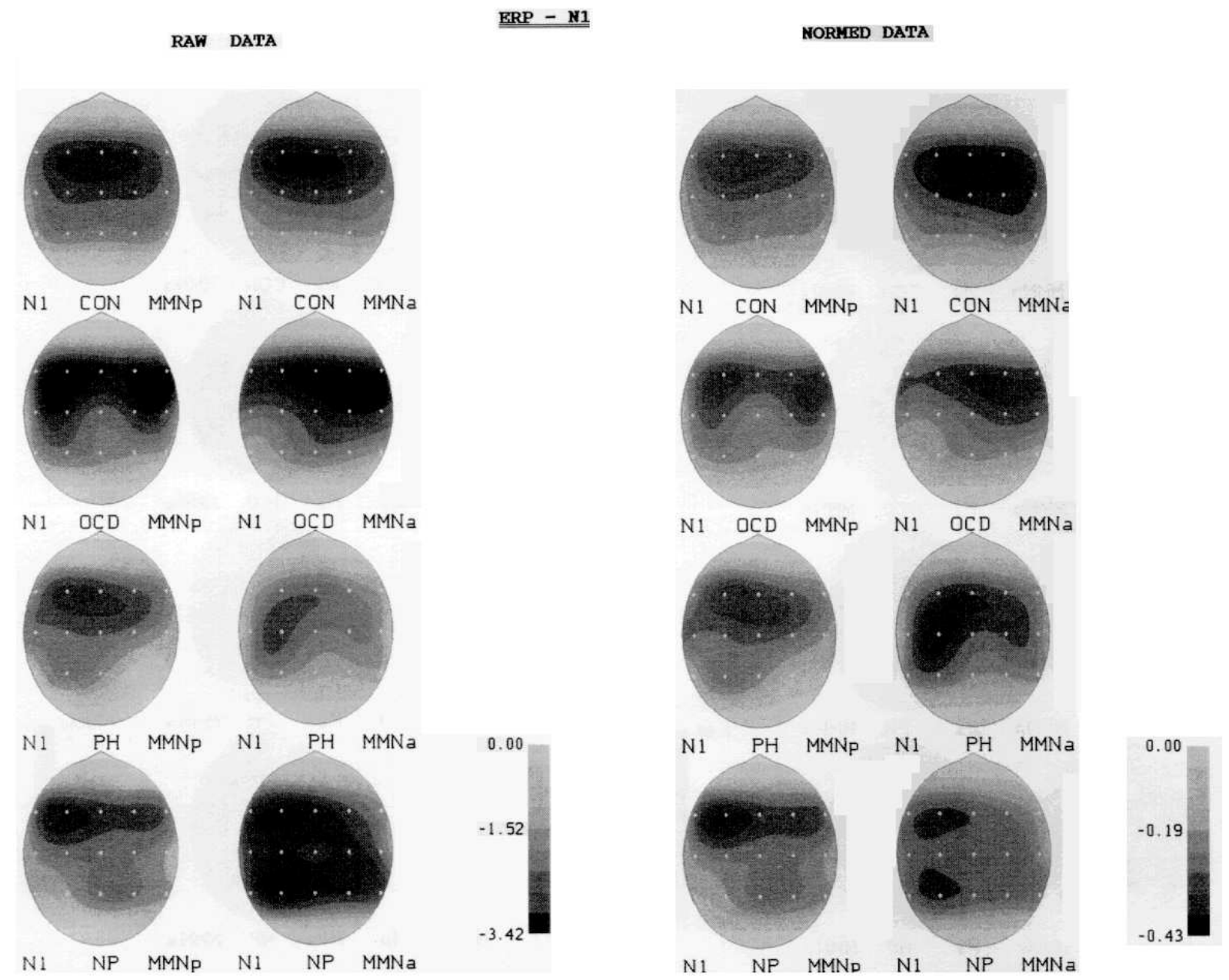

Figure 5. Topographic distribution of the amplitude of the N1-like component of the difference-wave. Raw data are shown (left) for 4 subject groups (see Figure 1 legend) in passive (MMNp) and active conditions $(\mathrm{MMNa})$. Note the trend for frontal values to increase in the active condition (but not for the PH group). Vector-normalized data are shown on the right. Note the broadly similar distribution of activity between groups and conditions but also the start of a lateral temporal representation in the NP group, better seen in the N2-1ike component (Fig. 2).

A common method for obtaining $\mathrm{MMN}$ is to offer a book to read while presenting the tones. There is, however, no clear demonstration that subjects are actively attending to the book. Negative findings (e.g., O'Donnell et al 1994) may result from obtaining records from patients that were not attending to or interested in anything at the time. The point is emphasized by these authors in their report of a "N1b" difference after subtracting ERPs to non-targets in the reading from a counting condition. This argument also applies to negative rep-orts associated with the presentation of an ancillary task. Thus Kathmann et al (1995) did not report whether patients were accurately tracking the visual target presented or that the task was indeed demanding of attention and effort.

In contrast, the discrimination performance of the schizophrenics here clearly shows that attention was focused on the task. By the same token we cannot rule out that their impaired accuracy and their impaired MMN could have a common basis; however, one may also ask if it was the "state" of focused attention that exaggerated a group difference in topography already present in the passive condition but, through the low amplitude, was masked by noise. On the 
limited data available in this study we are unable to rule this possibility in or out. Perusal of Figure 2 shows that all patients showed some "bilateralization" of MMN away from the midline in the passive condition. A comparison with the "N1-like precursor" in Figure 5 shows further that in NP patients negativity can localize at temporal sites, here on the left. Because of the small amplitudes involved and the integral variability of ERPs between schizophrenic patients (Roemer and Shagass 1990) this issue is unlikely to be resolved in this paradigm. It may be better to use stimulus locus in measuring $\mathrm{MMN}$ as this feature is reported to be more salient with regard to ERP records (Michie et al 1990).

The theoretical importance of the enhanced $M M N$ in an active condition lies with the demonstration that a degree of activation (e.g., here from controlled processing) normally results in increased differential processing of irrelevant stimuli (present results and Oades et al 1995). As reported in the Introduction, controlled processing is frequently impaired in schizophrenics and thus it was to be expected that such an impairment here would exaggerate the normal-psychotic difference in MMN. The question remains whether the effect is attributable to processing negativity associated with the target (Paavilainen et al 1993), active processing of irrelevant stimuli for comparative discrimination purposes, or is a spill-over from general interest, effort, or activation induced by the discrimination requirement as suggested by Oades et al (1995) and elaborated by Pribram and McGuinness (1993).

In a similar vein to our preferred explanation, O'Donnell et al (1994) have suggested that impairments in early negative components in passive and active conditions in schizophrenia might be attributed to general features of arousal and that the weakness in the difference-wave is restricted to the active condition. Further, in contrast to the proposal of Paavilainen et al (1993), it may be pointed out that measures of processing negativity have generated different results. In our patients there were much weaker group effects on processing negativity Oades et al (1996a) and Ward et al (1991) found that weak processing negativity in psychotic patients correlated with both negative and positive symptoms. These latter results show an effect of symptom-severity whereas the current report emphasizes an effect of symptom-type.

\section{Locus in Time}

Not all reported difference-waveforms show components other than the MMN before a late positivity, as can be seen in Figure 1, but early and late negative components can be seen in MMN reports (Winsberg et al 1993; O'Donnell et al 1994), in processing negativity (Ward et al 1991), and the negative difference (Woods et al 1993: see also Introduction). The presence of such deflections could reflect methods for selecting sweeps for averaging or the filters used. But as they appear more pronounced in the active condition it is also possible that they reflect the active attentional processes used. These, in turn, would be expected to incur selective inhibitory modulation of information flow as reflected by positive deflections in the waveform (Schupp et al 1994). Indeed a recent report using a passive/active two-tone paradigm found clear N1-like and N2-1ike amplitude reductions in the MMN difference waveform at latencies of about 102 and 210 $\mathrm{ms}$ for a diagnostic-ally unspecified group of schizophrenics (Javitt et al 1995c).

Generalizing, the PI-, P2-, and P3-like deflections showed a lack of similarity and have their own specific characteristics, as elaborated elsewhere (Oades et al 1996a). The N1-like peak did not show group differences and change like MMN with condition, although NP patients did show consider-able (left) temporal negativity recalling MMN. P1and P2-like peaks did not resemble the late positive complex, although naturally their size did mirror changes in the negative components at the same loci. It should not be surprising that these peaks show some specific features if the deflections reflect different functions. For example, Kofoed et al (1995) suggested that $\mathrm{MMN}$ in a pre-MMN positive component, determined magnetoencephalographically, represents the initiation of stimulus evaluation. 
In summary, in the present data the PI-like deflection in schizophrenics was more frontally localized than in OCD and control subjects. The P2-like deflection tended to be larger in schizophrenics and thus extended more frontally from a posterior locus that all groups had in common. The P3-like component was weakly expressed in schizophrenic subjects, but strongly expressed in OCD patients in the active condition.

Notably, the Nl-like deflection showed no statistically significant differences between conditions or groups; however, from Figures 1 and 2 it would seem that early negativity was most marked in OCD patients and showed an additional left temporal locus of activity in NP patients. These observations may obtain significance in future studies firstly, because early studies of MMN demonstrated an onset as early as $60 \mathrm{~ms}$ post-stimulus (review Näätänen 1990), secondly in the principle components analysis of Javitt et al (1995c) the N1-, N2- and P3-like components loaded exclusively with diagnosis onto the first, the most important factor, and thirdly, because increased excitability in the form of a negative shift has been reported from OCD patients (Towey et al 1993; Oades et al 1996a).

An attenuation of the enhancement of N1 in the attended channel was described for schizophrenics by Pritchard (1986). The interesting feature in the present results is that the consequences of this were seen at N2-1ike latencies: the usual MMN increase in the active condition seen in controls was not noted in schizophrenics; however the opposite, an enhancement, did seem to be occur-ing in OCD patients: a difference that needs to be confirmed in future studies. Further studies of the processing of irrelevant stimuli with difference-waves in divided attention paradigms may well make use of deflections other than MMN in the waveform to assist in delineating differences of processing strategies between schizophrenics, other patients, and healthy subjects.

It is appropriate to consider briefly the factor of the age of our subjects. The first question is whether the range of subjects' ages spread across an age-span of rapid development could have contributed to the differences recorded. This is unlikely firstly as the subjects were so closely matched, pairwise, for age (see Methods) and secondly we have examined the influence of development in normal subjects (8-22 $\mathrm{yr}$ of age) in this paradigm (Oades et al 1996b). Here we showed that while amplitudes can differ in size and locus in children younger than those tested here, latencies were the only MMN measures to change in adolescence (early frontal components were shorter in $14 \mathrm{y}$-olds and posterior late components were shorter in $17 \mathrm{y}$-olds). This might have contributed to the paucity of group latency differences, but otherwise the youth of our subjects may be considered representative of young adults.

\section{Late Positivity}

An updating function, attributed to the tone-elicited P3 (Donchin and Coles 1988) may also be appropriate to the late positivity to be found in the difference wave (Faux et al 1988). It may be elicited by pitch and frequency differences, even if there is no obvious consequence to any tone, as in the pass-ive condition. For healthy subjects these stimulus differences evidently take on more significance in a discrimination situation, even if the attention is focused on another stimulus, for the difference-P3 amplitude increases even after irrelevant stimuli, confirming the report of Oades et al (1995); however, consistent with data reviewed by Pritchard (1986) both PH and NP psychotic patients seemed to remain oblivious to these context dependent changes.

No topographic differences for the P3-1ike component in the difference-wave were found. This is consistent with the recent findings by Javitt et al (1995c) but contrasts with single tone elicited P3 components where a variety of lateralized changes between conditions have been noted to distinguish healthy from schizophrenic subjects (Faux et al 1988; McCarley et al 1993; Strik et al 1994; Oades et al 1996a).

\section{Locus in Space}

Normalization of the MMN differencewaveform data showed a striking reduction of MMN at frontal sites for NP patients. An 
apparent increase of negativity at lateral postero-temporal sites in NP was not seen in $\mathrm{PH}$ patients. This may have been overlooked in other studies either because this waveform has only been studied in passive conditions, the authors did not look for and analyze temporal site data appropriately (e.g., Javitt et al 1995c), or patient groups were derived from clinical diagnostic traits rather than current symptoms (Oades 1995).

The decrease could implicate hypo-frontal function, widely reported in schizophrenic patients with predominantly negative symptoms (e.g., Buchsbaum 1990) and a compensatory processing strategy being allocated to temporal lobes. This assumes dysfunction of a generator in frontal regions (Giard et al 1994), which otherwise has not been widely reported.

Alternatively, if the generator is located only in primary (N1, Scherg et al 1989) or secondary auditory association cortex (N2, O'Donnell et al 1993) - with the dipole oriented on the cortex curvature to record maximum negativity over frontal areas--then this orientation may have become altered in NP patients, who from their symptomatology may be those who show atrophy in temporal regions (Shenton et al 1992). This issue could be resolved by joint MRI-ERP studies of the type used by McCarley and colleagues.

A third possibility is that the temporal locus for MMN in NP patients is an arte-fact. The source of the artefact could derive from jaw movements that contribute to the variability commonly found in temporal ERP recordings. Even if such an artefact were contributory, it seems unlikely to be explanatory for the follow-ing reasons. The posterior temporal locus was statistically significant on the right, here, but marked bilaterally (Oades 1995, Fig. 4) in the active not the passive condition (Figure 2). Temp-oral loci for MMN have also been reported in young patients with complex tic or Tourette syndrome but in the passive condition (Oades et al 1996c). It is therefore enigmatic why such artefacts should be found in at least two patient groupings but not in OCD or attention-deficit-hyperactivity patients or normal subjects (young and old) all tested in the same paradigm. Further, it is not evident why the artefact should appear in the one or then in the other condition irrespective of task requirements. Lastly if the latency should be regarded as crucial for the artefact, we would note that the effect may occur more on the left side around $100 \mathrm{~ms}$ (Figure 5) but on the right at $200 \mathrm{~ms}$ in NP patients (Figure 2). Clearly the present result needs to be replicated, but it is useful to consider what biological bases may be common to the NP patients tested.

It is worth briefly considering the importance of the frontal areas, if not for the source of the MMN, but the source of the influence on auditory cortical MMN. MMN is a form of auditory working memory (see Introduction) and a recent report has shown that frontal working memory-related neural activity in monkeys was sensitive to D1 agents (Williams and Goldman-Rakic 1995). Indeed the neuronal effect of antagonists was more efficient for non-relevant stimulus fields than for target fields, which makes the results particularly interesting for MMN generated by non-targets. The authors noted that schizophrenic patients with reduced cortical dopamine activity, possibly as a result of neuroleptic therapy, showed improved working memory performance when given amphetamine: we have found that the NP patients in this study indeed showed reduced dopamine activity, as measured by the excretion of dopamine and homovanillic acid (Oades et al 1994). It would be of interest to see if a challenge with psychostimulants would have a normalizing effect on MMN specific to NP patients apparently not responding to neuroleptic treatment. The feature of neuroleptic non-response may be important here. While MMN amplitude was not found to be sensitive to neuroleptic dose either here or else-where (Javitt et al 1995c) one could still argue that the presence of an MMN at frontal recording sites in $\mathrm{PH}$ patients, albeit small, reflected their neuroleptic responsive state. It could be that differential (mesocortical) dopamine sensitivity of attentional mechanisms in NP and $\mathrm{PH}$ patients (Oades et al 1992a) and brought into play by the changeover from passive to active conditions here, is reflected in impaired 
frontal modulation of temporal lobe mechanisms, as proposed by Frith (1992), and here measured by MMN. This interpretation remains consistent with a potential source of stimulus comparator mechanisms in temporoparietal cortex that receive a large innervation from frontal and cingulate cortices (Oades et al 1996a; Woods et al 1993).

\section{Acknowledgments:}

We thank Dr. Ulrich Schall and Professor Christian Eggers for discussion and support. We are grateful to Dr. Margaret Möllering, Dr. Renate Schepker, Dr. Brigitte Zimmermann, Bernhard ROpcke, and Ewa Kulisch for clinical assistance. Rita Franzka, Jutta Haverkorn, and Robert Windelschmidt helped in the preparations for recording.

\section{References}

Andreasen NC (1983): The scale for the assessment of negative symptoms (SANS). lowa City, IA: University of lowa.

Andreasen NC (1984): The scale for assessment of positive symptoms (SAPS). lowa City, IA: University of lowa.

Buchsbaum MS (1990): The frontal lobes, basal ganglia and temporal lobes as sites for schizophrenia. Schizophr Bull 16:377-387.

Callaway E, Naghdi S (1981): An information processing model of schizophrenia. Arch Gen Psychiatry 38:339-347.

Carter CS, Robertson LC, Chaderjian MR, O'ShoraCelaya L, Nordahl TE (1994): Attentional asymmetry in schizophrenia: The role of illness subtype and symptomatology. Prog Neuropsychopharmacol Biol Psychiatry 18:661-683.

Catts SV, Shelley AM, Ward PB, Andrews SM, Michie PT, Liebert PT, McConaghy N (1992): Reduced mismatch negativity in neurolepticfree schizophrenics suggests a pre-attentive information processing deficit. Proceedings of EPICX (Eger, Hungary) p 25.

Catts SV, Shelley A-M, Ward PB, Liebert B, McConaghy N, Andrews S, Michie PT (1995): Brain potential evidence for an auditory sensory memory deficit in schizophrenia. Am J Psychiatry 152:213-219.

Cowan N, Winkler I, Teder W, Näätänen R (1993): Memory prerequisites of mismatch negativity in the auditory event-related potential (ERP). $J$ Exp Psychol Learn Mem Cogn 19:909-921.

Donchin E, Coles MGH (1988): Is the P300 component a manifestation of context updating? Behav Brain Sci 11:357- 427.

Faux SF, McCarley RW (1 passive 990): Analysis of scalp voltage MMN in Paranoid and Nonparanoid Patients asymmetries using Hotelling's T2 methodology. Brain Topogr 2:237-245.

Faux SF, Shenton ME, McCarley RW, Torello M, Duffy F (1988): Differentiation of schizophrenics and normal controls is enhanced by the Goodin subtraction procedure. Intern J Neurosci 39:117-135.

Frith CD (1992): The Cognitive Neuro-psychology of Schizophrenia, Hillsdale, NJ: Lawrence Erlbaum Associates.

Giard $\mathrm{MH}$, Perrin F, Echallier JF, Thevenet $\mathrm{M}$, Pernier J (1994): Dissociation of tempor-al and frontal components in the human auditory N1 wave: A scalp current density and dipole analysis, Electroencephalogr Clin Neurophysiol 192:238-252.

Hemsley DR (1994): A cognitive model for schizophrenia and its possible neural basis. Acta Psychiatr Scand suppl 384: 80-86.

Javitt DC, Doneshka P, Grochowski S, Ritter W (1995c): Impaired mismatch negativity generation reflects widespread dysfunction of working memory in schizophrenia. Arch Gen Psychiatry 52:550-558.

Javitt DC, Shelley A-M, Grochowski S, Lieberman JA (1995a): Mismatch negativity (MMN) in first episodic and chronic schizophrenic subjects. Schizophr Res 15:179-180.

Javitt DC, Doneshka P, Zylberman I, Ritter W, Vaughan HG (1993): Impairment of early cortical processing in schizophrenia: An eventrelated potential confirmation study. Biol Psychiatry 33:513-519.

Javitt DC, Schroeder CE, Steinschneider M, Arezzo JC, Ritter W, Vaughan HG (1995b): Cognitive event-related potentials in human and nonhuman primates: Implications for the PCP/NMDA model of schizophrenia. In: Karmos G, Molnar M, Csepe V, Czigler I, Desmedt JE (eds), Perspectives of EventRelated Potential Research. Electroencephalogr Clin Neurophysiol, suppl. 44: Amsterdam: Elsevier, 161-175.

Kathmann N, Wagner M, Rendtorff N, Engel RR (1995): Delayed peak latency of the mismatch 
negativity in schizophrenics and alcoholics. Biol Psychiatry 37:754-757.

Kofoed B, Bak CK, Rahn E, Saermark K (1995): Auditory event-related magnetic fields in a tone-duration discrimination task. Source localization for the mismatch field and for a new component M2. Acta Neurol Scand 91:362-371.

McCarley RW, Shenton ME, O'Donnell BF, Faux SF, Kikinis R, Nestor, PG, Jolesz FA (1993): Auditory P300 abnormalities and left posterior superior temporal gyrus volume reduction in schizophrenia. Arch Gen Psychiatry 50:190197.

Michie PT, Fox AM, Ward PB, Catts SV, McConaghy N (1990): Event-related potential indices of selective attention and cortical lateralization in schizophrenia. Psychophysiology 27: 209 -227.

Näätänen R (1990): The role of attention in auditory information processing as revealed by event-related potentials and other measures of cognitive function. Behav Brain Sci 13:201-288.

Naumann E, Huber C, Maier S, Plihal W, Wustmans A, Diedrich O, Bartussek D (1992): The scalp topography of P300 in the visual and auditory modalities: A comparison of three normalization methods and the control of statistical type II error. Electroencephalogr Clin Neurophysiol 83:254-264.

Oades RD (1995): Connections between studies of the neurobiology of attention, psychotic processes and event-related potentials. In: Karmos G, Molnar M, Csepe V, Czigler I, Desmedt JE (eds), Perspectives of EventRelated Potential Research. Electroencephalogr Clin Neurophysiol, suppl 44: Amsterdam: Elsevier, 428-438.

Oades, RD, Dittmann-Balcar A (1995): Mismatch negativity (MMN) is altered by directing attention. Neuroreport 6:1187- 1190.

Oades RD, Bunk D, Eggers C (1992a): Paranoid schizophrenics may not use irrelevant signals: The use of measures of blocking and of urinary dopamine. Acta Paedopsychiatr 55:183-184.

Oades RD, Dittmann-Balcar A, Zerbin D (1995): The topography of 4 ERP-subtraction waveforms derived from a 3-tone auditory oddball task in healthy young adults. Int J Neuroscience 81:265-281.

Oades RD, Dittmann-Balcar A, Zerbin D (1996b): Development and topography of auditory event-related potentials, mismatch and processing negativity from 8 to 22 years of age. Psychophysiology (In submission.)

Oades RD, Röpcke B, Eggers C (1994): Monoamine activity reflected in urine of young patients with obsessive compulsive disorder, psychosis with and without reality distortion and healthy subjects: an explorative analysis. I Neural Transm Gen Sect 96:143-159.

Oades RD, Zerbin D, Eggers C (1993): StimulusVergleichsprozesse bei psychotischen Jugendlichen mit paranoiden und nicht paranoiden Symptomen: "Mismatch Negativity" deutet auf differenzierte Beeinträchtigungen hin. In: Baumann P (ed), Biologische Psychiatrie der Gegenwart. Vienna: Springer- Verlag, pp 69-73.

Oades RD, Zerbin D, Dittmann-Balcar A, Eggers C (1996a): Auditory event- related potential (ERP) and difference-wave topography in schizophrenic patients with/without active hallucinations and delusions: a comparison with young OCD and healthy subjects. Int $J$ Psychophysiology (in press).

Oades RD, Zerbin D, Schall U, Eggers C (1992b): Stimulus-Vergleichsprozesse bei psychotischen Jugendlichen mit paranoiden und nichtparanoiden Symptomen: "Mismatch Negativity" deutet auf differenzierte Beeinträchtigungen. Fortschr Neurol Psychiatrie 60 suppl 1:30.

Oades RD, Dittmann-Balcar A, Schepker R, Eggers C, Zerbin D (1996c): Auditory event-related potentials (ERPs) and mismatch negativity (MMN) in healthy children and those with attention-deficit- or Tourette/tic symptoms. Biol Psychol 43:163-185.

O'Donnell BF, Hokama H, McCarley RW, Smith RS, Salisbury DF, Mondrow E, Nestor PG, Shenton ME (1994): Auditory ERPs to non-target stimuli in schizophrenia: Relationship to probability, task-demands and target ERPs. Int J Psychophysiology 17:219-231.

O'Donnell BF, Shenton MF, McCarley RW, Faux SF, Smith RS, Salisbury DF, Nestor PG, Pollak SD, Kikinis R, Jolesz FA (1993): The auditory N2 component in schizophrenia: Relationship to MRI temporal lobe gray matter and to other ERP abnormalities. Biol Psychiatry 34:26-40.

Paavilainen $P$, Tiitinen $H$, Alho $K$, Näätänen $R$ (1993): Mismatch negativity to slight pitch changes outside strong attentional focus. Biol Psychol 37:23-41. 
Pivik RT, Broughton R J, Coppola R, Davidson R J, Fox N, Nuwer MR (1993): Guidelines for the recording and quantitative analysis of electroencephalographic activity in research contexts. Psychophysiology 30:547-558.

Pribram KH, McGuinness D (1993): Attention and para-attentional processing: Event-related potentials as tests of a model. Ann NY Acad Sci 658:65-92.

Pritchard WS (1986): Cognitive event-related potential correlates of schizophrenia. Psychol Bull 100:43-66.

Rey MJ, Schulz P, Costa C, Dick P, Tissot R (1989): Guidelines for the dosage of neuroleptics. 1: Chlorpromazine equivalents of orally administered neuroleptics. Intern Clin Psychopharmacol 4:95-104.

Roemer RA, Shagass C (1990): Replication of an evoked potential study of lateralized dysfunction in schizophrenics. Biol Psychiatry 28:275-291.

Scherg M, Vajsar J, Picton TW (1989): A source analysis of the late human auditory evoked potentials. J Cog Neurosci 1:336-355.

Schupp HT, Lutzenberger W, Ran H, Birbaumer N (1994): Positive shifts of event-related potentials: A state of cortical disfacilitation as reflected by the startle reflex probe. Electroencephalogr Clin Neurophysiol 90:135144.

Shelley A-M, Ward PB, Catts SV, Michie PT, Andrews S, McConaghy N (1991): Mismatch negativity: An index of a pre-attentive processing deficit in schizophrenia. Biol Psychiatry 30:1059-1062.

Shenton MF, Kikinis R, Jolesz FA, Pollak SD, LeMay M, Wible CG, Hokama H, Martin J, Metcalf D, Coleman M, McCarley RW (1992): Abnormalities of the left temporal lobe and thought disorder in schizophrenia: A quantitative magnetic resonance imaging study. New Engl J Med 327:604-612.
Straube ER, Oades RD (1992): Schizophrenia: Empirical Research and Findings. New York: Academic Press.

Strauss ME (1993): Relations of symptoms to cognitive deficits in schizophrenia. Schizophr Bull 19:215-231.

Strik WK, Dierks T, Franzek E, Stoeber G, Maurer K (1994): P300 in schizophrenia: Interactions between amplitudes and topography. Biol Psychiatry 35:850-856.

Towey J, Bruder G, Tenke C, Leite P, DeCaria C, Friedman D, Hollander E (1993): Event-related potential and clinical correlates of neurodysfunction in obsessive-compulsive disorder. Psychiatry Res 49:167-181.

Umbricht D, Novak G, Bilder RM, Javitt DC, Pollack S, Lieberman JA, Kane J (1995): Mismatch negativity neuropsychological deficits and psychopathology in chronic schizophrenia. Schizophr Res 15:179.

Ward PB, Catts SV, Fox AM, Michie PT, McConaghy $N$ (1991): Auditory selective attention and event-related potentials in schizophrenia. Br J Psychiatry 158:534-539.

Williams GV, Goldman-Rakic P (1995): Modulation of memory fields by dopamine D1 receptors in prefrontal cortex. Nature 376:572-575.

Winsberg BG, Javitt DC, Silipo GS, Doneshka P (1993): Mismatch negativity in hyperactive children: Effects of methylphenidate. Psychopharmacol Bull 29:229-233.

Woods DL, Knight RT, Scabini D (1993): Anatomical substrates of auditory selective attention: Behavioral and electrophysiological effects of posterior association cortex lesions. Brain Res Cogn Brain Res 1:227-240.

Yamaguchi S, Tsuchiya H, Kobayashi S (1995): Electrophysiologic correlates of visuospatial attention shift. Electroencephalogr Clin Neurophysiol 94:450-461 